\title{
Reduction of Intrahepatic Tumour by Hepatic Arterial Infusion Chemotherapy Prolongs Survival in Hepatocellular Carcinoma
}

\author{
PIL SOO SUNG ${ }^{1,2, *}$, KEUNGMO YANG $^{1, *}$, SI HYUN BAE ${ }^{2,3}$, JUNG SUK OH $^{4}$, HO JONG CHUN $^{4}$, \\ HEE CHUL NAM $^{1}$, JEONG WON JANG $^{1,2}$, JONG YOUNG CHOI $^{1,2}$ and SEUNG KEW YOON ${ }^{1,2}$ \\ ${ }^{1}$ Department of Internal Medicine, College of Medicine, Seoul St. Mary's Hospital, \\ The Catholic University of Korea, Seoul, Republic of Korea; \\ ${ }^{2}$ The Catholic Liver Research Center, College of Medicine, \\ The Catholic University of Korea, Seoul, Republic of Korea; \\ ${ }^{3}$ Department of Internal Medicine, College of Medicine, St. Paul's Hospital, \\ The Catholic University of Korea, Seoul, Republic of Korea; \\ ${ }^{4}$ Department of Radiology, College of Medicine, Seoul St. Mary's Hospital, \\ The Catholic University of Korea, Seoul, Republic of Korea
}

\begin{abstract}
Background/Aim: This study aimed to identify the survival benefit of intrahepatic tumour control by hepatic arterial infusion chemotherapy (HAIC) in hepatocellular carcinoma (HCC) patients with portal vein tumour thrombus (PVTT) or extrahepatic metastasis. Patients and Methods: Between 2010 and 2017, a total of 187 consecutive patients with advanced HCC were treated with HAIC. The survival outcomes and response rates to HAIC were analysed. Results: The intrahepatic objective response $(O R)$ rate of all enrolled patients was $18.7 \%$. The survival outcome of patients with OR was significantly better from those without OR, irrespective of initial distant metastasis. Achievement of intrahepatic OR by HAIC and favourable liver function at the time of best response evaluation were two independent factors associated with better OS. Conclusion: HAIC-induced intrahepatic tumour reduction significantly prolonged patient survival, irrespective of PVTT or initial distant metastasis.
\end{abstract}

Hepatocellular carcinoma (HCC) is the fifth most common malignancy worldwide and the second most common cause of cancer-related mortality (1). For advanced HCC patients with portal vein tumour thrombus (PVTT) or extrahepatic metastasis,

\footnotetext{
*These Authors contributed equally to this work.

Correspondence to: Si Hyun Bae, MD, Ph.D., Department of Internal Medicine, College of Medicine, St. Paul's Hospital, The Catholic University of Korea, 180 Wangsan-ro, Dongdaemun-gu, Seoul 02559, Republic of Korea. Tel: +82 29582114, Fax: +82 234814025, e-mail: baesh@catholic.ac.kr

Key Words: Hepatic arterial infusion, intrahepatic tumor, survival, hepatocellular carcinoma, chemotherapy, treatment response.
}

sorafenib and lenvatinib are the first-line standard treatments to significantly improve survival outcomes, although their efficacy is modest and considerable adverse effects have been reported (2-4). Moreover, recent immune checkpoint inhibitors showed objective responses to only selected patients (5).

Hepatic arterial infusion chemotherapy (HAIC) is one of the alternative treatment options available for the patients with advanced HCC. HAIC achieves higher concentrations of the chemotherapeutic agents in the tumour with less systemic toxicity, by direct delivery of the drug, through an implantable port, into the liver (6). Several previous studies have demonstrated that treatment of HCC by HAIC results in better objective response (OR) and patient survival than by sorafenib (7-12). However, until recently, there has been no consensus to suggest HAIC as one of the standard treatment modalities of advanced HCC.

Mortality due to extrahepatic metastasis has been reported to be only $7.6 \%$ in advanced HCC; the leading cause of death was progression of intrahepatic disease (13). Several groups have reported that targeted control of intrahepatic tumours with transarterial chemoembolization (TACE) significantly prolongs survival in multinodular HCC patients without PVTT, even in patients with extrahepatic metastases (13-16). Nonetheless, the role of aggressive intrahepatic tumour control has not been clearly elucidated in more advanced HCC with PVTT. This study aimed to determine the survival benefit of intrahepatic tumour reduction by HAIC in advanced HCC patients with PVTT or extrahepatic metastases.

\section{Materials and Methods}

Study population. This study was approved by the Institutional Review Board of our Institute (KC18RESI0520). It is a retrospective study from a prospectively collected database. All 
Table I. Baseline characteristics of patients.

\begin{tabular}{|c|c|c|}
\hline \multirow[t]{2}{*}{ Variables } & \multicolumn{2}{|c|}{ Total $(n=187)$} \\
\hline & No. & $\%$ \\
\hline Mean age (year) & \multicolumn{2}{|c|}{$55.9 \pm 10.0$} \\
\hline \multicolumn{3}{|l|}{ Age } \\
\hline$<60$ & 123 & 65.8 \\
\hline$\geq 60$ & 64 & 34.2 \\
\hline \multicolumn{3}{|l|}{ Gender } \\
\hline Male & 152 & 81.3 \\
\hline Female & 35 & 18.7 \\
\hline \multicolumn{3}{|l|}{ Etiology } \\
\hline HBV & 155 & 82.9 \\
\hline $\mathrm{HCV}$ & 12 & 6.5 \\
\hline Alcohol & 10 & 5.3 \\
\hline $\mathrm{HBV}+\mathrm{HCV}$ & 1 & 0.5 \\
\hline Others & 9 & 4.8 \\
\hline \multicolumn{3}{|l|}{ Tumor maximal diameter } \\
\hline$<10 \mathrm{~cm}$ & 80 & 42.8 \\
\hline$\geq 10 \mathrm{~cm}$ & 107 & 57.2 \\
\hline \multicolumn{3}{|l|}{ Tumor number } \\
\hline Single & 66 & 35.3 \\
\hline Multiple & 121 & 64.7 \\
\hline \multicolumn{3}{|l|}{ Portal vein tumor thrombus } \\
\hline No & 33 & 17.6 \\
\hline Yes & 154 & 82.4 \\
\hline \multicolumn{3}{|l|}{ Vp stage } \\
\hline Vp 1 or 2 & 25 & 16.2 \\
\hline Vp 3 & 73 & 47.4 \\
\hline Vp 4 & 56 & 36.4 \\
\hline \multicolumn{3}{|l|}{ Serum AFP } \\
\hline$<400 \mathrm{ng} / \mathrm{ml}$ & 77 & 41.2 \\
\hline$\geq 400 \mathrm{ng} / \mathrm{ml}$ & 110 & 58.8 \\
\hline \multicolumn{3}{|l|}{ Child-Pugh class } \\
\hline A & 94 & 50.3 \\
\hline B & 93 & 49.7 \\
\hline $\mathrm{C}$ & 0 & 0 \\
\hline \multicolumn{3}{|l|}{ BCLC stage } \\
\hline A & 0 & 0 \\
\hline B & 24 & 12.8 \\
\hline $\mathrm{C}$ & 163 & 87.2 \\
\hline \multicolumn{3}{|l|}{ Extrahepatic metastasis } \\
\hline Yes & 47 & 25.1 \\
\hline No & 140 & 74.9 \\
\hline \multicolumn{3}{|l|}{ Extrahepatic metastasis } \\
\hline Lung & 19 & 10.2 \\
\hline Lymph node & 24 & 12.8 \\
\hline Adrenal gland & 3 & 1.6 \\
\hline Bone & 6 & 3.2 \\
\hline Brain & 1 & 0.5 \\
\hline Other sites & 2 & 1.1 \\
\hline Mean HAIC session number & \multicolumn{2}{|c|}{$4.6 \pm 3.3$} \\
\hline Median HAIC session number & \multicolumn{2}{|c|}{4.0} \\
\hline \multicolumn{3}{|l|}{ Previous treatment } \\
\hline TACE & 77 & 41.2 \\
\hline RFA & 12 & 6.4 \\
\hline TARE & 4 & 2.1 \\
\hline Liver resection & 8 & 4.3 \\
\hline Sorafenib & 6 & 3.2 \\
\hline RT & 10 & 5.3 \\
\hline
\end{tabular}

HAIC: Hepatic arterial infusion chemotherapy; HBV: hepatitis B virus; HCV: hepatitis C virus; AFP: alpha fetoprotein; BCLC: Barcelona Clinical Liver Cancer; TACE: transarterial chemoembolization; RFA: radiofrequency ablation; TARE: transarterial radioembolization; RT: radiation therapy.
Table II. Intrahepatic response at the best response evaluation.

\begin{tabular}{|c|c|c|c|}
\hline \multirow[t]{2}{*}{$\begin{array}{l}\text { Intrahepatic tumor } \\
\text { response }\end{array}$} & \multicolumn{2}{|c|}{$\begin{array}{l}\text { Extrahepatic metastasis } \\
\text { at the initial diagnosis }\end{array}$} & \multirow[t]{2}{*}{$\begin{array}{c}\text { Total } \\
\text { patients }\end{array}$} \\
\hline & Yes & No & \\
\hline Complete response $(\%)$ & $1(2.1)$ & $3(2.1)$ & $4(2.1)$ \\
\hline Partial response (\%) & $6(12.8)$ & $25(17.9)$ & $31(16.6)$ \\
\hline Stable disease $(\%)$ & $29(61.7)$ & $80(57.1)$ & $109(58.3)$ \\
\hline Progressive disease $(\%)$ & $11(23.4)$ & $32(22.9)$ & $23(23.0)$ \\
\hline Total $(\%)$ & $47(100)$ & $140(100)$ & $187(100)$ \\
\hline
\end{tabular}

HAIC: Hepatic arterial infusion chemotherapy.

medical records of the patients diagnosed with $\mathrm{HCC}$ between January 2010 and December 2017 were reviewed. In our institution, HAIC tends to be the preferred method over sorafenib for the treatment of advanced HCC when it is accompanied by PVTT or the tumour type is infiltrative, even in patients with impaired liver function. During this period, unresectable HCC patients treated by HAIC were enrolled using the following inclusion criteria; age 2080 years, Child-Pugh class A or B, Eastern Cooperative Oncology Group (ECOG) performance status below 2, no evidence of bone marrow suppression (white blood cell $\geq 3,000 / \mu 1$, hemoglobin $\geq 8$ $\mathrm{g} / \mathrm{dl}$, and platelet $\geq 7.5 \times 10^{4} / \mu \mathrm{l}$ ), and preserved renal function (serum creatinine level below $2.0 \mathrm{mg} / \mathrm{dl}$ ). Patients treated with sorafenib before HAIC were excluded. Finally, a total of 187 consecutive patients with advanced HCC treated with HAIC were enrolled. All patients enrolled in this study were followed up until May 2018, and the patients' survival was confirmed by the National Health Insurance Service.

Diagnosis of HCC. The latest guideline from American Association for the Study of Liver Diseases (AASLD) and Asian Pacific Association for the Study of the Liver (APASL) were used for the diagnosis of HCC $(1,17)$. The classification of PVTT was based on the Vp stages (18); Vp 1 was defined as tumour invasion distal to the second branch of the portal vein; Vp 2 and $V p 3$ were defined as invasions in the second and first branch of the portal vein, respectively; Vp 4 was defined as presence of a tumour thrombus in the main trunk of the portal vein or a portal vein branch contralateral to the primarily involved lobe (18).

Hepatic arterial infusion chemotherapy and response evaluation. The detailed HAIC protocol was reported in previous studies (19, $20)$. At least two interventional radiologists with over 5 years of experience performed all the procedures. Chemotherapeutic agents in protocol were 5 -fluorouracil $(5-\mathrm{FU})\left(500 \mathrm{mg} / \mathrm{m}^{2}\right)$ for 3 days and cisplatin $\left(60 \mathrm{mg} / \mathrm{m}^{2}\right)$ on the second day. All patients were administrated 5-hydroxytryptamine 3 antagonist as the prophylactic anti-emetic drug after treatments. In order to prevent the chemotherapy-induced nephrotoxicity, intravenous hydration was routinely performed before and after the treatments. A recent randomized study demonstrated that adding adriamycin to conventional HAIC (composed of 5-FU plus cisplatin) did not result in a survival benefit (21). Therefore, in this study, patients treated with the regimen of HAIC composed of 5-FU, adriamycin, and cisplatin were also included. 

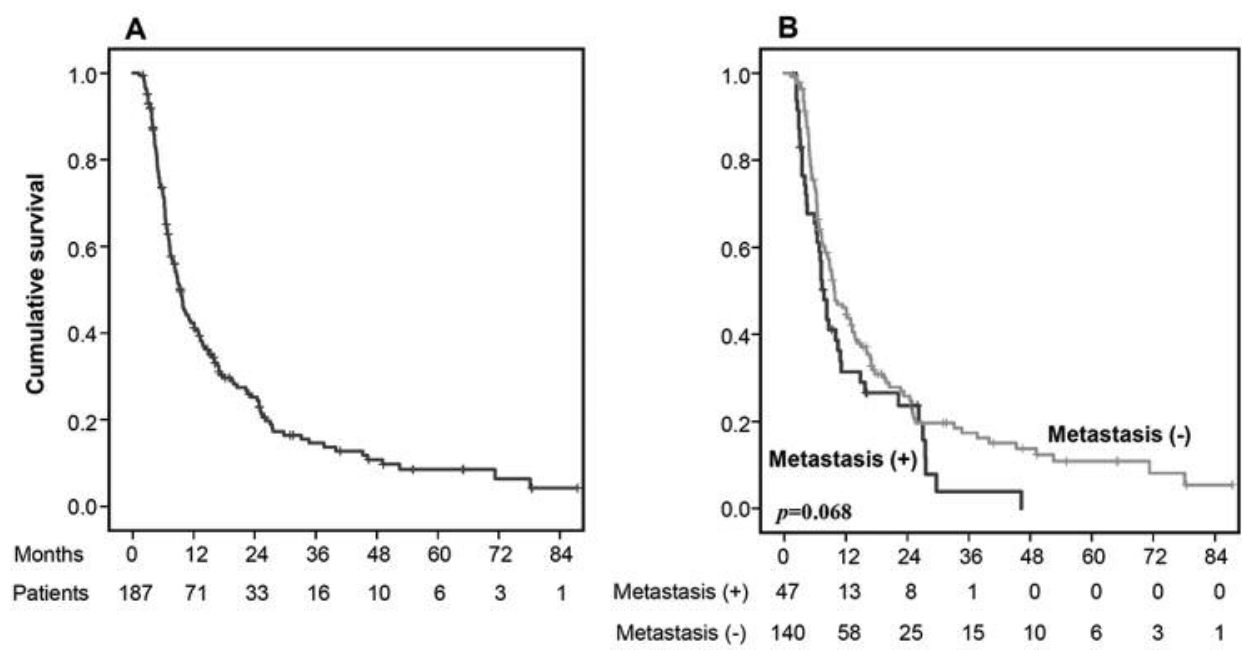

Figure 1. Kaplan-Meier survival curves for overall survival. (A) Overall survival in all patients. (B) Overall survival according to the presence of initial extrahepatic metastasis.

HAIC was repeated at 4-6 week intervals when the patients did not present disease progression or a serious complication by the treatments. Liver function was estimated using the Child-Pugh classification at each cycle. In all patients who underwent HAIC, treatment response was evaluated using follow up multiphasic CT or MRI after two or three cycles of treatments. Treatment response evaluation was based on the modified Response Evaluation Criteria in Solid Tumours (mRECIST) (22). In mRECIST, infiltrative-type HCC is considered as a non-target lesion. In these cases, RECIST was applied instead. PVTT, which is also considered as a non-target lesion in mRECIST, was excluded when tumour response was evaluated. The best intrahepatic response was defined as the most favourable result of dynamic imaging studies during HAIC.

Statistical analyses. Continuous variables in the baseline characteristics were described as the means with the range of standard deviation. Categorical variables were compared using the chi-square test and Fisher's exact test. Patients' survival was calculated from the date HAIC started until the date of death. The overall survival (OS) was estimated by Kaplan-Meier method and compared using the logrank test. Multivariate analysis with a Cox proportional hazard model was performed to find factors affecting patients' OS. $p$-Value below 0.05 was used to define statistical significance. The Statistical Package for the Social Sciences (SPSS, version 24.0, Inc., Chicago, IL, USA) was used for all statistical analyses.

\section{Results}

Baseline characteristics. Table I summarizes the baseline clinical characteristics of the enrolled patients. The mean age was 55.9 years, and $81.3 \%$ of the patients were male. The major cause of the underlying liver disease was hepatitis B virus infection (82.9\%). Most patients had PVTT at baseline $(82.4 \%)$. Among the patients with PVTT, 25 (16.2\%) had Vp 1 or $2,73(47.4 \%)$ had Vp 3, and $56(36.4 \%)$ had Vp 4
PVTT. Among the enrolled patients, 47 (25.1\%) patients had extrahepatic metastasis when HAIC was started. Median HAIC session number was 4.0. Overall, 85 patients had a previous local treatment history before the start of HAIC and the most frequent previous treatment modality was TACE.

Intrahepatic response at the best response evaluation. The best intrahepatic treatment response was assessed according to mRECIST after 2 or 3 cycles of HAIC (Table II). The intrahepatic OR rate was $18.7 \%$ in all patients. When the patients were subdivided into two groups according to the presence of initial extrahepatic metastasis, $3(2.1 \%)$ patients showed intrahepatic complete response (CR), 25 (17.9\%) showed intrahepatic partial response (PR), and 32 (22.9\%) showed intrahepatic progressive disease (PD), in the patients without extrahepatic metastasis. In the group with extrahepatic metastasis, $1(2.1 \%)$ patient showed intrahepatic CR, $6(12.8 \%)$ showed intrahepatic PR and 11 (23.4\%) showed intrahepatic PD.

Overall survival of the enrolled patients. Next, we analysed the OS (Figure 1) using the Kaplan-Meier method. Figure 1A shows the OS of the total enrolled patients; the median survival period was 9.4 months. The cumulative OS rates at $6,12,24$, and 36 months were $71.9 \%, 42.4 \%, 25.2 \%$, and $14.6 \%$, respectively. The median survival period was 7.7 months in the patients with extrahepatic metastasis and 9.8 months in the patients without extrahepatic metastasis (Figure 1B).

Overall survival according to the best intrahepatic response. To evaluate the importance of the reduction of intrahepatic tumour burden by HAIC, the OS was analysed according to the best intrahepatic response. The patients were subdivided 

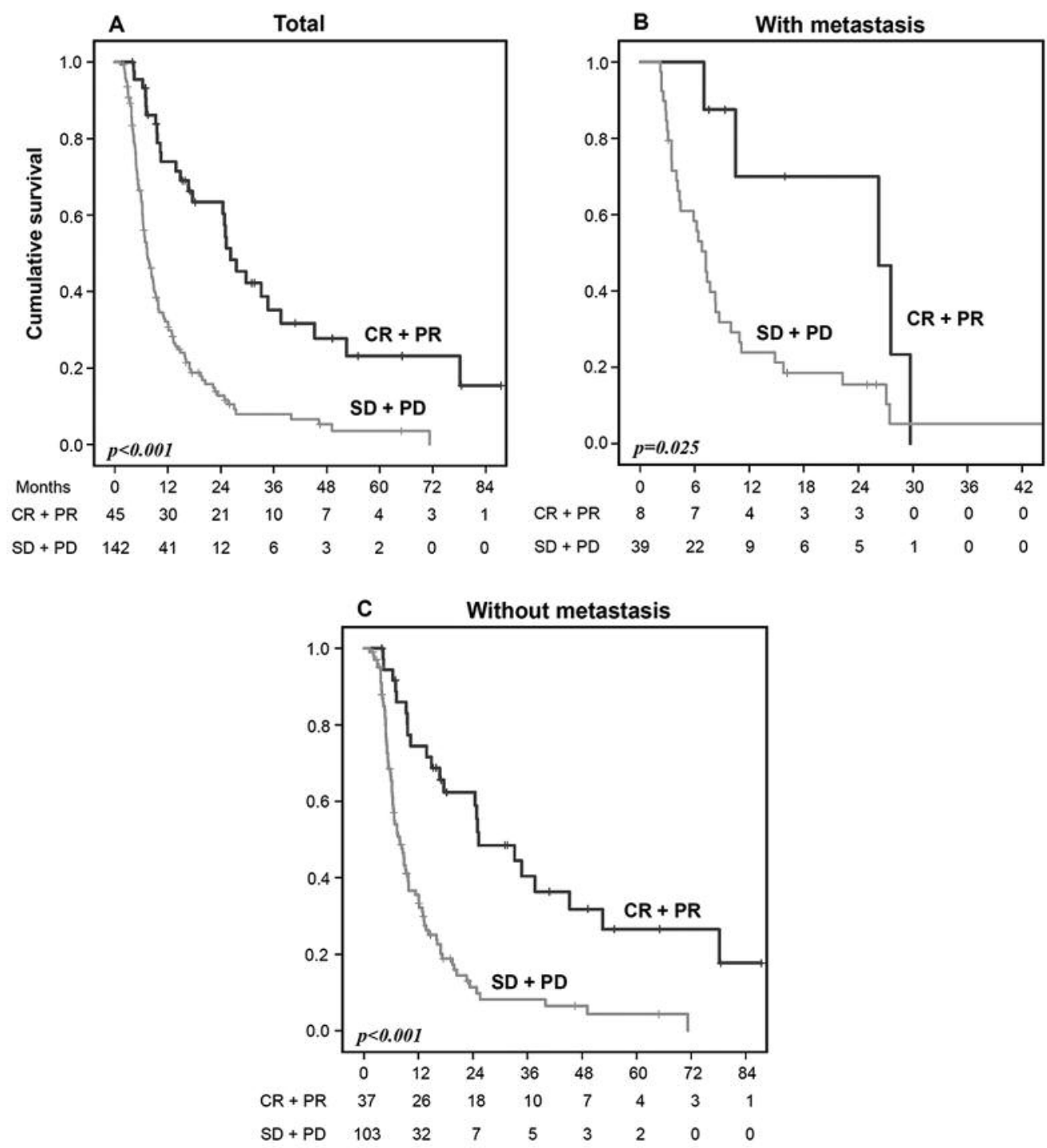

Figure 2. Kaplan-Meier survival curves for overall survival according to best intrahepatic response to hepatic arterial infusion chemotherapy. (A) All patients. (B) Patients with extrahepatic metastases. (C) Patients without extrahepatic metastases. CR: Complete response; PR: partial response; SD: stable disease; PD: progressive disease; HAIC: hepatic arterial infusion chemotherapy.

into two groups by the response to HAIC: CR + PR vs. SD + $\mathrm{PD}$ (Figure 2). Analyses were performed in the following three groups: all patients, patients with extrahepatic metastasis, and patients without extrahepatic metastasis (Figure 2). In the group with all patients, the patients with intrahepatic $\mathrm{CR}$ and PR after HAIC showed significantly better survival outcomes than patients with intrahepatic SD and PD (Figure 2A, $p<0.001)$. Similar to these results, the patients with extrahepatic metastasis were found to have a significant survival benefit when intrahepatic CR or PR was obtained by HAIC (Figure 2B, $p=0.025$ ). The patients without extrahepatic metastasis also had significantly better survival outcomes with intrahepatic CR or PR (Figure 2C, $p<0.001$ ).
Next, the subgroup analyses were performed with patients having PVTT according to the best intrahepatic response. Similarly to the parent group, patients having PVTT with intrahepatic PR and CR showed better survival outcomes than those with intrahepatic SD and PD by HAIC irrespective of the initial status of distant metastasis. In addition, patients with PVTT were subdivided into two groups by the level of PVTT (Figure 3). For patients with Vp 3 or 4 PVTT, there was also a significant improvement in OS when CR or PR was obtained by HAIC (Figure 3B, $p<0.001$ ).

Prognostic factors for favourable survival. Univariate analysis was performed to find the factors affecting OS and intrahepatic 

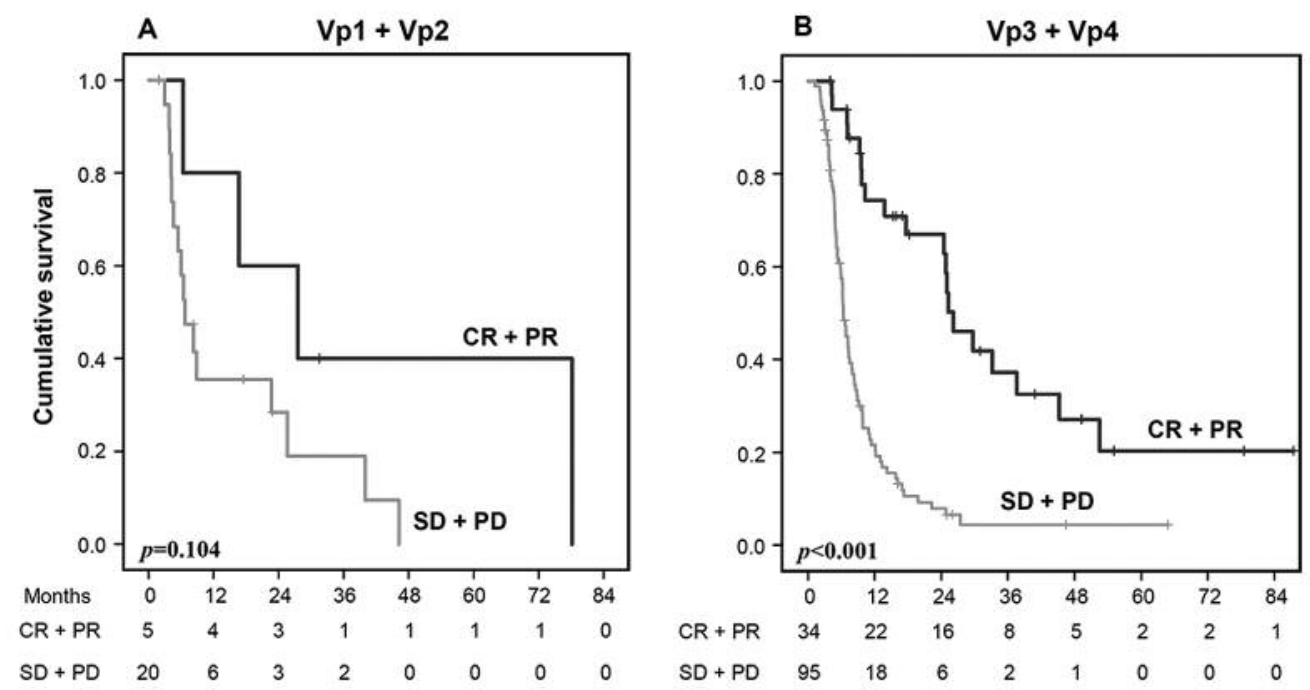

Figure 3. Kaplan-Meier survival curves for overall survival in patients with portal vein tumour thrombus according to best intrahepatic response. (A) Patients with Vp1 or Vp2 portal vein tumour thrombus. (B) Patients with Vp3 or Vp4 portal vein tumour thrombus. PVTT: Portal vein tumour thrombus; CR: complete response; PR: partial response; S: stable disease; PD: progressive disease.

PFS (Table III). Tumour maximal diameter $<10 \mathrm{~cm}(p=0.011)$, AFP response $(>20 \%$ decrease after the first HAIC, $p=0.008)$ and obtaining favourable intrahepatic OR $(p<0.001)$ were found to be the factors associated with better OS.

Subsequently multivariate analyses with Cox proportional hazard model was performed to investigate independent prognostic factors affecting OS (Table III). The analyses were conducted in two models with different number of parameters. In model 1 , the significant factors influencing the favourable survival outcomes were as follows: ChildPugh class $A$ at the best treatment response evaluation (hazard ratio $(\mathrm{HR})=0.586,95 \%$ confidence interval $(\mathrm{CI})=0.409-0.840, p=0.004)$ and obtaining favourable intrahepatic $\mathrm{OR}(\mathrm{HR}=0.330,95 \% \mathrm{CI}=0.213-0.512, p<0.001)$. In model 2 , the same variables as in model 1 were associated with favourable survival outcomes.

\section{Discussion}

The prognosis of advanced HCC with PVTT or extrahepatic metastasis is extremely poor. The therapeutic goal is usually to prolong patient survival with maintaining the hepatic reserve. Sorafenib, a multikinase inhibitor, has since long been standard treatment for advanced HCC in the BCLC staging system (23). However, the Sorafenib HCC Assessment Randomised Protocol (SHARP) trial demonstrated that sorafenib only modestly increased survival in patients with BCLC stage C disease from 7.9 months to 10.7 months (4, 24). For the patients in the Asian-Pacific area, the survival benefit was even less than that observed globally, probably because these patients presented with more aggressive disease and involvement of portal vein, as well as predominant aetiology of chronic hepatitis B $(4,25)$. Therefore, a major cause of mortality in patients with advanced HCC in AsianPacific area is largely due to progression of intrahepatic tumour and resultant hepatic dysfunction. At this point, our study has critical implications. We confirmed that HAIC results in a significant survival benefit in advanced $\mathrm{HCC}$, because it results in significant intrahepatic tumour reduction even in patients with Vp3 or Vp4 PVTT. To the best of our knowledge, thus far no study has focused on the impact of intrahepatic tumour control by HAIC in advanced HCC even with PVTT or extrahepatic metastasis.

Previously, Terashima et al. demonstrated that targeting intrahepatic tumours may confer survival benefit for patients with advanced HCC even after sorafenib treatment is discontinued (26). In line with this study, our study further emphasizes that HAIC takes a critical role in the control of intrahepatic tumours of patients with BCLC-C diseases. The presence of intrahepatic tumours was one of the critical prognostic factors of OS for patients with advanced HCC, even for those with extrahepatic spread treated by sorafenib (26). Therefore, targeted control of intrahepatic tumours will clearly influence the prognosis of these patients. As mentioned in the introduction section, extrahepatic tumours account for only $7.6 \%$ of cause of death in advanced HCC (26).

One of the factors that significantly affected OS in the multivariate analysis was the maintenance of favourable liver function (Child Pugh class A) after 1st round of HAIC (Table III). A recent study reported that maintaining better the hepatic reserve after HAIC had a prognostic effect on patient survival outcomes in advanced HCC (27). In our study, 
Table III. Univariate and multivariate analysis for overall survival.

\begin{tabular}{|c|c|c|c|c|c|c|}
\hline \multirow[t]{3}{*}{ Variables } & \multicolumn{2}{|c|}{ Univariate analysis for OS } & \multicolumn{4}{|c|}{ Multivariate analysis for OS } \\
\hline & \multirow{2}{*}{$\begin{array}{c}\text { Median } \\
\text { OS (months) }\end{array}$} & \multirow[b]{2}{*}{$p$-Value } & \multicolumn{2}{|c|}{ Model 1} & \multicolumn{2}{|c|}{ Model 2} \\
\hline & & & $p$-Value & $\mathrm{HR}(95 \% \mathrm{CI})$ & $p$-Value & $\mathrm{HR}(95 \% \mathrm{CI})$ \\
\hline \multicolumn{7}{|l|}{ Gender } \\
\hline Male & 9.2 & 0.282 & & & & \\
\hline Female & 10.9 & & & & & \\
\hline \multicolumn{7}{|l|}{ Age } \\
\hline$<60$ & 8.8 & 0.189 & 0.683 & $1.079(0.748-1.557)$ & & \\
\hline$\geq 60$ & 12.1 & & & & & \\
\hline \multicolumn{7}{|l|}{ Etiology } \\
\hline HBV & 9.6 & 0.592 & & & & \\
\hline $\mathrm{HCV}$ & 8.6 & & & & & \\
\hline Alcohol & 4.4 & & & & & \\
\hline $\mathrm{HBV}+\mathrm{HCV}$ & 9.6 & & & & & \\
\hline Others & 3.9 & & & & & \\
\hline \multicolumn{7}{|c|}{ Tumor maximal diameter } \\
\hline$<10 \mathrm{~cm}$ & 13.7 & 0.011 & 0.081 & $0.735(0.528-1.036)$ & 0.091 & $0.710(0.478-1.056)$ \\
\hline$\geq 10 \mathrm{~cm}$ & 7.7 & & & & & \\
\hline \multicolumn{7}{|l|}{ Tumor number } \\
\hline Single & 9.2 & 0.732 & & & & \\
\hline Multiple & 9.4 & & & & & \\
\hline \multicolumn{7}{|c|}{ Portal vein tumor thrombus } \\
\hline No & 14.8 & 0.16 & & & & \\
\hline Yes & 8.3 & & & & & \\
\hline \multicolumn{7}{|l|}{ Serum AFP } \\
\hline$<400 \mathrm{ng} / \mathrm{ml}$ & 13.3 & 0.08 & 0.079 & $0.740(0.528-1.036)$ & 0.117 & $0.721(0.479-1.085)$ \\
\hline$\geq 400 \mathrm{ng} / \mathrm{ml}$ & 7.4 & & & & & \\
\hline \multicolumn{7}{|l|}{ AFP response ${ }^{\dagger}$} \\
\hline No & 8.3 & 0.008 & & & & \\
\hline Yes & 13 & & & & & \\
\hline \multicolumn{7}{|c|}{ Initial Child-Pugh class } \\
\hline A & 9.6 & 0.374 & & & & \\
\hline $\mathrm{B}$ or $\mathrm{C}$ & 8.3 & & & & & \\
\hline \multicolumn{7}{|c|}{ Follow-up Child-Pugh class } \\
\hline A & 16 & 0.001 & 0.004 & $0.586(0.409-0.840)$ & 0.035 & $0.622(0.401-0.967)$ \\
\hline $\mathrm{B}$ or $\mathrm{C}$ & 7.3 & & & & & \\
\hline \multicolumn{7}{|c|}{ Initial BCLC stage } \\
\hline $\mathrm{B}$ & 16 & 0.058 & & & & \\
\hline $\mathrm{C}$ & 8.6 & & & & & \\
\hline \multicolumn{7}{|c|}{ Previous treatment history } \\
\hline No & 7.2 & 0.141 & & & & \\
\hline Yes & 11.4 & & 0.387 & $1.116(0.829-1.623)$ & & \\
\hline \multicolumn{7}{|c|}{ Extrahepatic metastasis } \\
\hline No & 7.7 & 0.068 & & & & \\
\hline Yes & 9.8 & & 0.204 & $1.276(0.876-1.859)$ & & \\
\hline \multicolumn{7}{|c|}{ Best intrahepatic OR rate } \\
\hline $\mathrm{CR}$ and $\mathrm{PR}$ & 26.2 & $<0.001$ & $<0.001$ & $0.330(0.213-0.512)$ & $<0.001$ & $0.314(0.181-0.545)$ \\
\hline SD and PD & 7.3 & & & & & \\
\hline
\end{tabular}

OS: Overall survival; HR: hazard ratio; CI: confidence interval; HBV: hepatitis B virus; HCV: hepatitis C virus; AFP: alpha fetoprotein; HAIC: hepatic arterial infusion chemotherapy; BCLC: Barcelona Clinical Liver Cancer; OR: objective response; CR: complete response; PR: partial response; SD: stable disease; PD: progression disease. ${ }^{\dagger}$ AFP response was defined with a $>20 \%$ decrease after the first HAIC. ${ }^{\ddagger}$ Follow-up ChildPugh class was evaluated after the first HAIC.

although about $50 \%$ of the enrolled patients were in ChildPugh class B initially, the univariate and multivariate analyses confirmed that maintaining Child-Pugh class A after 1st round of HAIC, not initial liver function, was significantly associated with improved patients' OS (Table III). These results are consistent with the previous report, and suggest that patient liver function should always be reevaluated when 1st round of HAIC is completed. 
The present study has several important limitations. First, this study was performed in a single institution which could cause a selection bias. Second, the number of patients with extrahepatic metastasis was relatively small. However, to the best of our knowledge, this study included the largest number of advanced HCC patients with extrahepatic metastasis treated by HAIC. Third, since the treatment modality was limited to HAIC, the efficacy of intrahepatic tumour control by other treatments available for advanced HCC remains unclear. We tried to perform similar analyses with patients who underwent sorafenib treatment at the same period. However, there were only 3 patients with intrahepatic $\mathrm{PR}+\mathrm{CR}$ among more than 250 patients after sorafenib treatment, which made the statistical analyses impossible.

In conclusion, intrahepatic tumour reduction by HAIC was found to prolong advanced HCC patients' survival, irrespective of PVTT and the initial status of extrahepatic metastasis. It is critical that the intrahepatic tumour burden be reduced aggressively, even when patients have extrahepatic metastasis or PVTT.

\section{Conflicts of Interest}

The Authors have no conflicts of interest to declare regarding this study.

\section{Authors' Contributions}

Pil Soo Sung, Keungmo Yang, and Si Hyun Bae contributed to conception, design, acquisition, analysis, and interpretation of data. Jung Suk Oh and Ho Jong Chun contributed to acquisition and interpretation of data. Hee Chul Nam, Jeong Won Jang, Jong Young Choi and Seung Kew Yoon contributed to conception and design. Pil Soo Sung wrote the manuscript.

\section{Acknowledgements}

This research was supported by Basic Science Research Program througth the National Research Foundation of Korea (NRF) funded by the Ministry of Science, ICT \& Future Planning (2017R1A2B4010197). This work was also supported by Research Fund of Seoul St. Mary's Hospital, The Catholic University of Korea.

\section{References}

1 Heimbach JK, Kulik LM, Finn RS, Sirlin CB, Abecassis MM, Roberts LR, Zhu AX, Murad MH and Marrero JA: AASLD guidelines for the treatment of hepatocellular carcinoma. Hepatology 67(1): 358-380, 2018. PMID: 28130846. DOI: 10.1002/hep.29086

2 Pinter $\mathrm{M}$ and Peck-Radosavljevic M: Review article: systemic treatment of hepatocellular carcinoma. Aliment Pharmacol Ther 48(6): 598-609, 2018. PMID: 30039640. DOI: 10.1111/ apt.14913

3 Kudo M, Finn RS, Qin S, Han KH, Ikeda K, Piscaglia F, Baron A, Park JW, Han G, Jassem J, Blanc JF, Vogel A, Komov D, Evans TRJ, Lopez C, Dutcus C, Guo M, Saito K, Kraljevic S,
Tamai T, Ren M and Cheng AL: Lenvatinib versus sorafenib in first-line treatment of patients with unresectable hepatocellular carcinoma: a randomised phase 3 non-inferiority trial. Lancet 391(10126): 1163-1173, 2018. PMID: 29433850. DOI: 10.1016/ S0140-6736(18)30207-1

4 Sung PS, Park HL, Yang K, Hwang S, Song MJ, Jang JW, Choi JY, Yoon SK, Yoo IR and Bae SH: (18)F-fluorodeoxyglucose uptake of hepatocellular carcinoma as a prognostic predictor in patients with sorafenib treatment. Eur J Nucl Med Mol Imaging 45(3): 384-391, 2018. PMID: 29124280. DOI: 10.1007/s00259017-3871-5

5 El-Khoueiry AB, Sangro B, Yau T, Crocenzi TS, Kudo M, Hsu C, Kim TY, Choo SP, Trojan J, Welling TH Rd, Meyer T, Kang YK, Yeo W, Chopra A, Anderson J, Dela Cruz C, Lang L, Neely J, Tang H, Dastani HB and Melero I: Nivolumab in patients with advanced hepatocellular carcinoma (CheckMate 040): an openlabel, non-comparative, phase $1 / 2$ dose escalation and expansion trial. Lancet 389(10088): 2492-2502, 2017. PMID: 28434648. DOI: 10.1016/S0140-6736(17)31046-2

6 Obi S, Sato S and Kawai T: Current status of hepatic arterial infusion chemotherapy. Liver Cancer 4(3): 188-199, 2015. PMID: 26674592. DOI: 10.1159/000367746

7 Song MJ: Hepatic artery infusion chemotherapy for advanced hepatocellular carcinoma. World J Gastroenterol 21(13): 38433849, 2015. PMID: 25852268. DOI: 10.3748/wjg.v21.i13.3843

8 Kim HY, Kim JD, Bae SH, Park JY, Han KH, Woo HY, Choi JY, Yoon SK, Jang BK, Hwang JS, Kim SG, Kim YS, Seo YS, Yim HJ, Um SH and Korean Liver Cancer Study Group: A comparative study of high-dose hepatic arterial infusion chemotherapy and transarterial chemoembolization using doxorubicin for intractable, advanced hepatocellular carcinoma. Korean J Hepatol 16(4): 355, 2010. PMID: 21415578. DOI: 10.3350/kjhep.2010.16.4.355

9 Oh MJ, Lee HJ and Lee SH: Efficacy and safety of hepatic arterial infusion chemotherapy for advanced hepatocellular carcinoma as first-line therapy. Clin Mol Hepatol 19(3): 288299, 2013. PMID: 24133667. DOI: 10.3350/cmh.2013.19.3.288

10 Ikeda M, Shimizu S, Sato T, Morimoto M, Kojima Y, Inaba Y, Hagihara A, Kudo M, Nakamori S, Kaneko S, Sugimoto R, Tahara T, Ohmura T, Yasui K, Sato K, Ishii H, Furuse J and Okusaka T: Sorafenib plus hepatic arterial infusion chemotherapy with cisplatin versus sorafenib for advanced hepatocellular carcinoma: randomized phase II trial. Ann Oncol 27(11): 2090-2096, 2016. PMID: 27573564. DOI: 10.1093/annonc/mdw323

11 Choi JH, Chung WJ, Bae SH, Song DS, Song MJ, Kim YS, Yim HJ, Jung YK, Suh SJ, Park JY, Kim DY, Kim SU and Cho SB: Randomized, prospective, comparative study on the effects and safety of sorafenib vs. hepatic arterial infusion chemotherapy in patients with advanced hepatocellular carcinoma with portal vein tumor thrombosis. Cancer Chemother Pharmacol 82(3): 469-478, 2018. PMID: 29982870. DOI: 10.1007/s00280-0183638-0

12 Yang H, Woo HY, Lee SK, Han JW, Jang B, Nam HC, Lee HL, Lee SW, Song DS, Song MJ, Oh JS, Chun HJ, Jang JW, Lozada A, Bae SH, Choi JY and Yoon SK: A comparative study of sorafenib and metronomic chemotherapy for Barcelona Clinic Liver Cancer-stage $\mathrm{C}$ hepatocellular carcinoma with poor liver function. Clin Mol Hepatol 23(2): 128-137, 2017. PMID: 28494528. DOI: $10.3350 / \mathrm{cmh} .2016 .0071$ 
13 Uchino K, Tateishi R, Shiina S, Kanda M, Masuzaki R, Kondo Y, Goto T, Omata M, Yoshida H and Koike K: Hepatocellular carcinoma with extrahepatic metastasis: clinical features and prognostic factors. Cancer 117(19): 4475-4483, 2011. PMID: 21437884. DOI: $10.1002 / \mathrm{cncr} .25960$

14 Jung SM, Jang JW, You CR, Yoo SH, Kwon JH, Bae SH, Choi JY, Yoon SK, Chung KW, Kay CS and Jung HS: Role of intrahepatic tumor control in the prognosis of patients with hepatocellular carcinoma and extrahepatic metastases. J Gastroenterol Hepatol 27(4): 684-689, 2012. DOI: 10.1111/ j.1440-1746.2011.06917.x

15 Yoo DJ, Kim KM, Jin YJ, Shim JH, Ko GY, Yoon HK, Sung KB, Lee JL, Kang YK, Lim YS, Lee HC, Chung YH, Lee YS and Suh DJ: Clinical outcome of 251 patients with extrahepatic metastasis at initial diagnosis of hepatocellular carcinoma: does transarterial chemoembolization improve survival in these patients? J Gastroenterol Hepatol 26(1): 145-154, 2011.

16 Yoo JJ, Lee JH, Lee SH, Lee M, Lee DH, Cho Y, Lee YB, Yu SJ, Kim HC, Kim YJ, Yoon JH, Kim CY and Lee HS: Comparison of the effects of transarterial chemoembolization for advanced hepatocellular carcinoma between patients with and without extrahepatic metastases. PLoS One 9(11): e113926, 2014. PMID: 25427152. DOI: 10.1371/journal.pone.0113926

17 Omata M, Cheng AL, Kokudo N, Kudo M, Lee JM, Jia J, Tateishi R, Han KH, Chawla YK, Shiina S, Jafri W, Payawal DA, Ohki T, Ogasawara S, Chen PJ, Lesmana CRA, Lesmana LA, Gani RA, Obi S, Dokmeci AK and Sarin SK: Asia-Pacific clinical practice guidelines on the management of hepatocellular carcinoma: a 2017 update. Hepatol Int 11(4): 317-370, 2017. PMID: 28620797. DOI: 10.1007/s12072-017-9799-9

18 Yamamoto Y, Ikoma H, Morimura R, Shoda K, Konishi H, Murayama Y, Komatsu S, Shiozaki A, Kuriu Y, Kubota T, Nakanishi M, Ichikawa D, Fujiwara H, Okamoto K, Sakakura C, Ochiai $\mathrm{T}$ and Otsuji E: Post-hepatectomy survival in advanced hepatocellular carcinoma with portal vein tumor thrombosis. World J Gastroenterol 21(1): 246-253, 2015. PMID: 25574098. DOI: 10.3748/wjg.v21.i1.246

19 Song DS, Song MJ, Bae SH, Chung WJ, Jang JY, Kim YS, Lee SH, Park JY, Yim HJ, Cho SB, Park SY and Yang JM: A comparative study between sorafenib and hepatic arterial infusion chemotherapy for advanced hepatocellular carcinoma with portal vein tumor thrombosis. J Gastroenterol 50(4): 445454, 2015. PMID: 25027973. DOI: 10.1007/s00535-014-0978-3

20 Kim SH, Oh JS, Chun HJ, Choi BG and Lee HG: Dual-Port versus mono-port implantation for intra-arterial chemoinfusion therapy for treatment of hepatocellular carcinoma in patients with anatomic hepatic artery variation. J Vasc Interv Radiol 30(1): 2330, 2019. PMID: 30297310. DOI: 10.1016/ j.jvir.2018.06.006
21 Song MJ, Bae SH, Chun HJ, Choi JY, Yoon SK, Park JY, Han KH, Kim YS, Yim HJ, Um SH, Chung WJ, Hwang JS, Cho SB and Eun JR: A randomized study of cisplatin and 5-FU hepatic arterial infusion chemotherapy with or without adriamycin for advanced hepatocellular carcinoma. Cancer Chemother Pharmacol 75(4): 739-746, 2015. PMID: 25663125. DOI: 10.1007/s00280-015-2692-0

22 Leneioni $\mathrm{R}$ and Llovet J: Modified RECIST (mRECIST) assessment for hepatocellular carcinoma. Semin Liver Dis 30(1): 52-60, 2010. PMID: 20175033. DOI: 10.1055/s-0030-1247132

23 Llovet JM, Villanueva A, Lachenmayer A and Finn RS: Advances in targeted therapies for hepatocellular carcinoma in the genomic era. Nat Rev Clin Oncol 12(7): 408-424, 2015. PMID: 26054909. DOI: 10.1038/nrclinonc.2015.103

24 Llovet JM, Zucman-Rossi J, Pikarsky E, Sangro B, Schwartz M, Sherman M and Gores G: Hepatocellular carcinoma. Nat Rev Dis Primers 2: 16018, 2016. PMID: 27158749. DOI: 10.1038/ nrdp. 2016.18

25 Kim DY, Kim HJ, Han KH, Han SY, Heo J, Woo HY, Um SH, Kim YH, Kweon YO, Lim HY, Yoon JH, Lee WS, Lee BS, Lee HC, Ryoo BY and Yoon SK: Real-life experience of sorafenib treatment for hepatocellular carcinoma in Korea: From GIDEON Data. Cancer Res Treat 48(4): 1243-1252, 2016. PMID: 26910470. DOI: $10.4143 /$ crt.2015.278

26 Terashima T, Yamashita T, Horii R, Arai K, Kawaguchi K, Kitamura K, Yamashita T, Sakai Y, Mizukoshi E, Honda M and Kaneko S: Potential efficacy of therapies targeting intrahepatic lesions after sorafenib treatment of patients with hepatocellular carcinoma. BMC Cancer 16(1): 338, 2016. PMID: 27246496. DOI: $10.1186 / \mathrm{s} 12885-016-2380-4$

27 Terashima T, Yamashita T, Arai K, Kawaguchi K, Kitamura K, Yamashita T, Sakai Y, Mizukoshi E, Honda M and Kaneko S: Beneficial effect of maintaining hepatic reserve during chemotherapy on the outcomes of patients with hepatocellular carcinoma. Liver Cancer 6(3): 236-249, 2017. PMID: 28626734. DOI: $10.1159 / 000472262$ 